\title{
CURCUMIN MICROENCAPSULATION USING CHITOSAN-ETHYL CELLULOSE-GMS MIXTURE FOR PRESERVATION OF MUCOADHESIVE PROPERTIES AND CONTROLLED RELEASE KINETIC
}

\author{
DENI RAHMAT ${ }^{1 *}$, YUNAHARA FARIDA ${ }^{1}$, NOVI YANTIH ${ }^{1}$, GITA SEPTYANA DEWI ${ }^{1}$, SARAH ANGELA PURNAMA ${ }^{1}$
}

1Faculty of Pharmacy, Pancasila University, Srengseng Sawah, Jagakarsa, Jakarta Selatan 12640, Indonesia

Email: denrerum@gmail.com

Received: 17 Aug 2021, Revised and Accepted: 25 Nov 2021

\section{ABSTRACT}

Objective: This research aimed to prepare curcumin microcapsules by the spray drying method and to evaluate their characteristics.

Methods: The microcapsules were prepared by the spray drying method. The generated microcapsules were evaluated for organoleptic, morphology, particle size, the percentage of curcumin and water content. Furthermore, the release of curcumin from the microcapsules was tested in vitro and compared to uncoated curcumin powder. In addition, the mucoadhesive properties of uncoated curcumin powder and curcumin microcapsules were also evaluated.

Results: The results showed that the microcapsules had spherical shape with particle size in the range of 100-1009 $\mu$ m and water content of $9.34 \%(w / w) ~(F I I I)$ and $8.09 \%(w / w)$ (FVI). The release of curcumin from its uncoated powder and the microcapsules FVI within $8 \mathrm{~h}$ were $8.87 \%$ and $26.32 \%(\mathrm{w} / \mathrm{w})$, respectively. It was found that the mucoadhesive properties of microcapsules FVI were better than those of FIII and uncoated curcumin powder. Microcapsules FVI rendered the cumulative amount of curcumin remaining on the intestinal mucosa of $55 \%(\mathrm{w} / \mathrm{w})$ within $3 \mathrm{~h}$.

Conclusion: Accordingly, curcumin microcapsules generated by spray drying could be further formulated into various solid dosage forms for a better therapeutic effect.

Keywords: Curcumin, Microencapsulation, Mucoadhesive, Release

(c) 2022 The Authors. Published by Innovare Academic Sciences Pvt Ltd. This is an open access article under the CC BY license (https://creativecommons.org/licenses/by/4.0/] DOI: https://dx.doi.org/10.22159/ijap.2022v14i1.42899. Journal homepage: https://innovareacademics.in/journals/index.php/ijap

\section{INTRODUCTION}

Turmeric rhizome has been widely used as a raw material for medicinal herbals. The benefits of turmeric rhizome in the treatment of various diseases are mainly due to the presence of curcuminoid compounds which consist of curcumin and desmethoxycurcumin. Therefore, turmeric rhizome devotes a great potential to be developed into a pharmaceutical preparation. However, curcumin has a bitter taste with an unpleasant odour and the storage will reduce the levels of curcumin $[1,2]$.

One of the methods to encounter its shortcomings is microencapsulation. The advantages of microencapsulation are the comparatively long durability of the entrapped active compounds. The microencapsulation can result in a high flowability of the powder thus the possibility of arising out inhomogeneous mixture is avoided. In addition, microencapsulation can provide the protection of unstable active compounds. The decrease in the content can be covered by coating it with the wall materials of microcapsules $[3,4]$.

Moreover, microencapsulation is one of the techniques for controlling the release of active compounds. Its applications in pharmaceutical formulation include long-acting drugs, taste masking, suspensions preparations, and single-layer tablets containing compounds with chemical incompatibilities. Moreover, the microcapsules can be further formulated into various solid dosage forms [5-7]. In previous studies, the use of chitosan as a matrix in nanocurcumin could increase the solubility of curcumin [8, 9]. Therefore, in this study, the microencapsulation of curcumin was developed using the same formula as the nanocurcumin as reported in previous studies with slightly modification by adding ethyl cellulose and glyceryl monostearate (GMS). Ethylcellulose was added to the formula to provide a sustained release profile of the resulting microcapsules.

\section{MATERIALS AND METHODS}

\section{Materials}

Curcumin (PT. Plamed Green Science, Xi'an, China), chitosan (Bio Chitosan, Cirebon, Indonesia), ethyl cellulose (Sigma-Aldrich, Singapore), propylene glycol (Sigma-Aldrich, Singapore), ethanol, glyceryl monostearate (GMS) (Sigma-Aldrich, Singapore), dimethylsulfocside (DMSO) (Sigma-Aldrich, Singapore), distilled water, porcine small intestine, dialysis cassette MWCO $2 \mathrm{kDa}$ (Thermo Fisher Scientific, Singapore), phosphate buffer (SigmaAldrich, Singapore), $\mathrm{NaOH}$, and $\mathrm{HCl}$.

Table 1: Formulation of curcumin microcapsules with propylene glycol

\begin{tabular}{llll}
\hline Ingredient & Formula & & FII \\
\cline { 2 - 4 } & F1 & $0.5 \mathrm{~g}$ & $0.5 \mathrm{~g}$ \\
\hline Curcumin & $0.5 \mathrm{~g}$ & $40 \mathrm{ml}$ & $40 \mathrm{ml}$ \\
Ethyl cellulose 1\%(w/v) & $40 \mathrm{ml}$ & - & - \\
Chitosan 1\% (w/v) & $40 \mathrm{ml}$ & $40 \mathrm{ml}$ & - \\
Chitosan 1.5\% (w/v) & - & - & $40 \mathrm{ml}$ \\
Chitosan 2\% (w/v) & - & $20 \mathrm{ml}$ & $20 \mathrm{ml}$ \\
Propylene glycol (v/v) & $20 \mathrm{ml}$ & $20 \mathrm{ml}$ & $20 \mathrm{ml}$ \\
Ethanol 70\% (v/v) & $20 \mathrm{ml}$ & $20 \mathrm{ml}$ & $20 \mathrm{ml}$ \\
DMSO 10\%(v/v) & $20 \mathrm{ml}$ & \\
\hline
\end{tabular}


Table 2: Formulation of curcumin microcapsules with GMS

\begin{tabular}{llll}
\hline Ingredient & Formula & \\
\cline { 2 - 3 } & FIV & FV \\
\hline Curcumin & $0.5 \mathrm{~g}$ & $0.5 \mathrm{~g}$ \\
Ethyl cellulose 1\%(w/v) & $40 \mathrm{ml}$ & $40 \mathrm{ml}$ & FVI \\
Chitosan 1\% (w/v) & $40 \mathrm{ml}$ & - & $0.5 \mathrm{~g}$ \\
Chitosan 1.5\%(w/v) & - & $40 \mathrm{ml}$ \\
Chitosan 2\%(w/v) & - & - & - \\
GMS & $2 \mathrm{~g}$ & $2 \mathrm{~g}$ & - \\
Ethanol 70\% (v/v) & $20 \mathrm{ml}$ & $20 \mathrm{ml}$ & $40 \mathrm{ml}$ \\
DMSO 10\%(v/v) & $20 \mathrm{ml}$ & $20 \mathrm{ml}$ \\
\hline
\end{tabular}

\section{Preparation of microcapsules}

Chitosan was dissolved in $1 \%(\mathrm{v} / \mathrm{v})$ glacial acetic acid to obtain a concentration of $1 \%, 1.5 \%$ and $2 \%(\mathrm{w} / \mathrm{v})$ while $1 \%(\mathrm{w} / \mathrm{v})$ ethyl cellulose solution was prepared in $100 \mathrm{ml} 96 \%(\mathrm{v} / \mathrm{v})$ ethanol using a magnetic stirrer. $0.5 \mathrm{~g}$ of curcuminoid was dissolved in a solvent mixture $(20 \mathrm{ml}$ propylene glycol, $20 \mathrm{ml}$ ethanol $70 \%(\mathrm{v} / \mathrm{v})$, and $20 \mathrm{ml}$ DMSO $10 \%(\mathrm{v} / \mathrm{v})$ ) as shown in table 1 , while table 2 shows the formulation using GMS instead of propylene glycol. Afterwards, $40 \mathrm{ml}$ of chitosan solution was added to each formula with different concentrations $(1 \%, 1.5 \%$, and $2 \%$ $(\mathrm{w} / \mathrm{v})$ ). The final mixture was dried using a spray dryer with an inlet temperature of $180^{\circ} \mathrm{C}$ and an outlet temperature of $80^{\circ} \mathrm{C}[8,9]$.

\section{Microcapsules organoleptic and morphology}

In organoleptic observations, the shape and colour of the microcapsules were recorded. Meanwhile, the morphology of the microcapsules was examined using EVO MA 10 Scanning Electron Microscopy (SEM).

\section{Particle size distribution}

Measurement of particle size distribution was carried out using the optical microscopy method. Briefly, the optical microscope was calibrated before use. The microcapsules were placed on a glass slide and added with distilled water. The particle size of microcapsules was measured under the microscopes by using the 100X ruler (a millimeter ruler as seen under 100 power magnification) after the suspension was covered with a glass slide [10].

\section{The percentage of curcumin in microcapsules}

$10 \mathrm{mg}$ of the microcapsules were weighed and dissolved in $10 \mathrm{ml}$ of $70 \%(\mathrm{v} / \mathrm{v})$ ethanol in a $25 \mathrm{ml}$ Erlenmeyer flask. Afterward, $2 \mathrm{ml}$ of the solution was diluted with $98 \mathrm{ml}$ of $70 \%(\mathrm{v} / \mathrm{v})$ ethanol. The absorption of the final solution was measured at the maximum wavelength of curcumin using a UV-Vis spectrophotometer.

\section{Water content}

A water content test was conducted by a Karl Fischer moisture meter. A $50 \mathrm{mg}$ sample was weighed in a container; then the sample was inserted into the instrument.

\section{Release study of curcumin from microcapsules in vitro}

$25 \mathrm{ml}$ of curcumin microcapsules were put in a dialysis cassette and $25 \mathrm{ml}$ of phosphate buffer pH 6.8 was added. The release study was performed in a $2000 \mathrm{ml}$ beaker with phosphate buffer $\mathrm{pH} 6.8$ as a medium at a temperature of $37{ }^{\circ} \mathrm{C} \pm 0.5{ }^{\circ} \mathrm{C}$. The medium was stirred using a magnetic stirrer at $50 \mathrm{rpm} .10 \mathrm{ml}$ of sample was withdrawn at a predetermined time $(15 ; 30 ; 45 ; 60 ; 120 ; 180 ; 240 ; 300 ; 360$; $420 ; 480 \mathrm{~min})$. The absorption of each sample was recorded using a UV-visible spectrophotometer at its maximum wavelength $[11,12]$.

\section{Evaluation of mucoadhesive properties}

The porcine small intestine was prepared and cut into $3 \mathrm{~cm} \times 8 \mathrm{~cm}$ dimensions. The outer part of the intestine was glued to a PVC pipe cut in half and placed on the flat table at an angle of $45^{\circ}$ and a temperature of $37{ }^{\circ} \mathrm{C}$ with $100 \%$ humidity. The intestine was moistened for $5 \mathrm{~min}$. afterward, $150 \mathrm{mg}$ dry powder of curcumin microcapsules were placed on the mucous surface of the small intestine with an area of $1 \mathrm{~cm}^{2}$. The microcapsules were washed off with $0.1 \mathrm{M}$ phosphate buffer solution $\mathrm{pH} 6.8$ at $37^{\circ} \mathrm{C}$ with a flow rate of $1 \mathrm{ml} / \mathrm{min}$ for $3 \mathrm{~h}$. After a predetermined time point $(1,2,3 \mathrm{~h})$, the intestine was incubated with $300 \mathrm{ml}$ of $96 \%(\mathrm{v} / \mathrm{v})$ ethanol for 20 min in a $500 \mathrm{ml}$ beaker glass. The fluorescence intensity was measured using a spectrofluorometer at an excitation wavelength of $413 \mathrm{~nm}$ and an emission wavelength of $522 \mathrm{~nm}$ [13].

\section{RESULTS}

\section{Preparation of microcapsules}

Curcumin has poor solubility in water and is easily degraded by the light. Therefore, curcumin was prepared in the form of microcapsules using the spray drying method, which is simple and easy. Curcumin has a high solubility in DMSO and in ethanol. However, DMSO has high toxicity, so its concentration in the formula should not be more than $10 \%(\mathrm{v} / \mathrm{v})$. Therefore, propylene glycol was mixed to increase the solubility of curcumin [3-7].

\section{Microcapsules organoleptic and morphology}

The precipitation of curcumin was observed during the solubilization of curcumin in chitosan solution. Only $2 \%(\mathrm{w} / \mathrm{v})$ chitosan solution (FIII and FVI) could optimally solubilized curcumin. This could be caused by the addition of chitosan at the highest concentration. Therefore, only FIII and FVI were then spray dried and evaluated for their characteristics [8,9]. The results of organoleptic evaluation of microcapsules FIII and F4VI showed that the microcapsules produced were dark red in colour (fig. 1) and odourless.

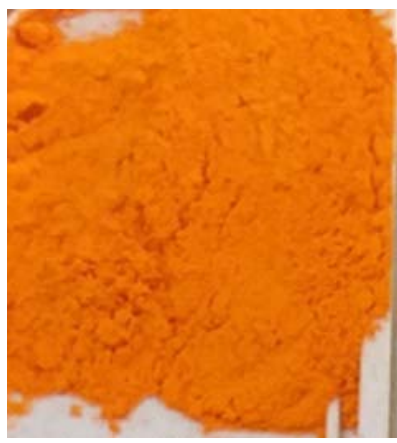

A

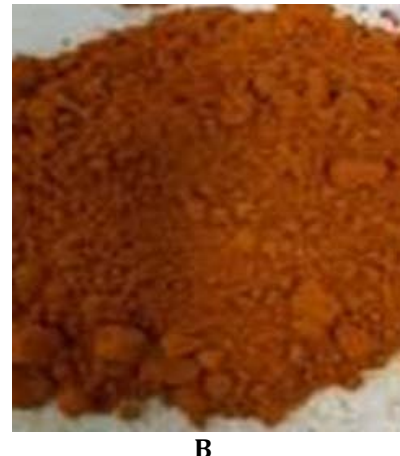

B

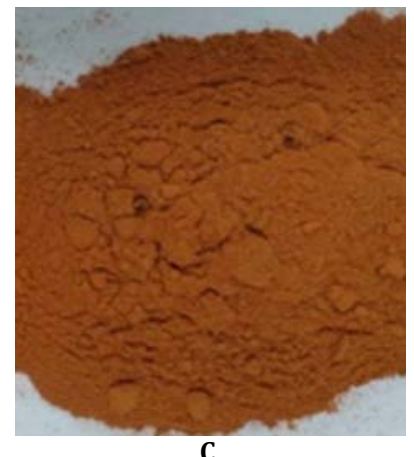

C

Fig. 1: Curcumin (A), microcapsules FIII (B) and microcapsules FVI (C) 
Curcumin was surrounded by the wall material that could act as a physical barrier. The wall material was a mixture of chitosanethyl cellulose-GMS designated to homogeneously entrap curcumin as GMS could be able to disperse the resulting suspension in the solvents. The morphology of microcapsules was recorded by SEM to identify the surface of the microcapsules and to investigate whether there were pores formed on the walls [14]. The microcapsule morphology affects the release of active compounds. The result of SEM evaluation can be seen in fig. 2 .

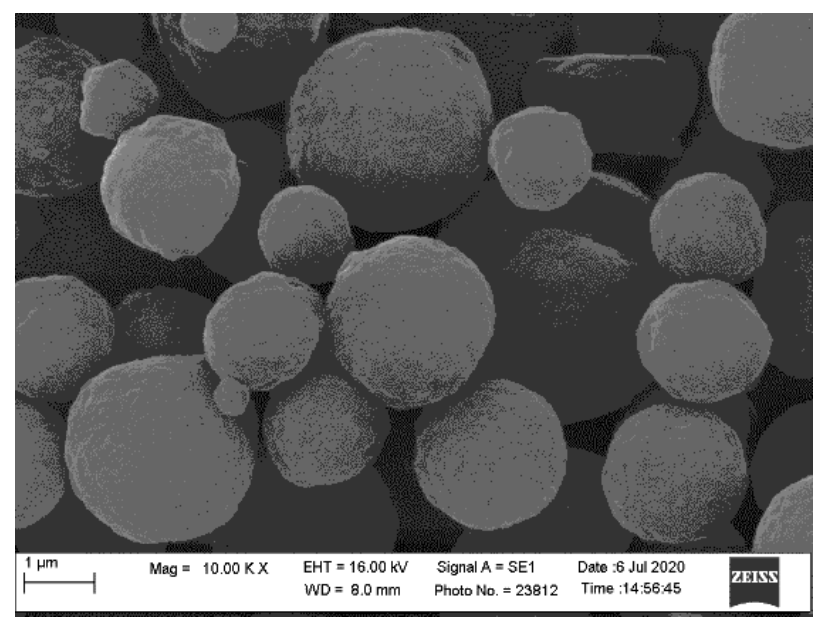

A

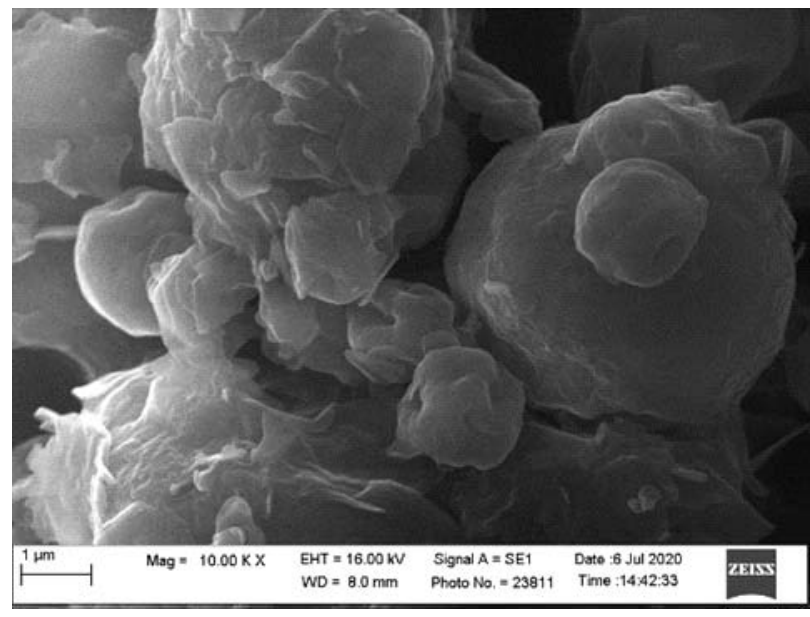

B

Fig. 2: Morphology of microcapsules FIII (A) and FVI (B)

\section{Particle size distribution}

The solvents were used to solubilize curcumin in chitosan and ethyl cellulose solution. The particle size distribution was carried out to evaluate the uniformity of microcapsules and to determine the microcapsule size ranges. Three hundred microcapsules were measured using optical microscopy using 10x magnification [10]. Based on the data on the size distribution, it can be found that microcapsules FIII had the largest particle size in the range of $100-150 \mu \mathrm{m}$ with a frequency of $42 \%$; thus almost $50 \%$ of the particles had a mean size range of $125 \mu \mathrm{m}$ as shown in table 3 . In addition, $26.67 \%$ of particles exerted a mean size range of $176 \mu \mathrm{m}$. Hence, only $31.33 \%$ of particles were bigger than 202 $\mu \mathrm{m}$ in diameter as depicted in fig. 3. The particle size distribution of microcapsules FVI (table 4) was similar to that of FIII. Based on fig. 3, the microcapsules with narrow size distribution could be achieved with a proper concentration of GMS.

Table 3: Particle size distribution of microcapsules FIII

\begin{tabular}{llll}
\hline Size range $(\boldsymbol{\mu m})$ & Mean size range $(\boldsymbol{\mu m})$ & Number of particles in each range* & \% Frequency* \\
\hline $100-150$ & 125 & $125.67 \pm 1.53$ & $41.89 \pm 0.51$ \\
$151-201$ & 176 & $79.67 \pm 1.53$ & $26.56 \pm 0.51$ \\
$202-252$ & 227 & $26.00 \pm 4.58$ & $8.67 \pm 1.53$ \\
$253-303$ & 278 & $24.67 \pm 5.51$ & $8.22 \pm 1.84$ \\
$304-354$ & 329 & $14.00 \pm 1.00$ & $4.67 \pm 0.33$ \\
$355-405$ & 380 & $10.67 \pm 4.04$ & $3.56 \pm 1.35$ \\
$406-456$ & 431 & $7.33 \pm 4.51$ & $2.44 \pm 1.50$ \\
$457-507$ & 482 & $5.33 \pm 0.58$ & $1.78 \pm 0.19$ \\
$508-558$ & 533 & $3.00 \pm 1.00$ & $1.00 \pm 0.33$ \\
$559-609$ & 584 & $3.67 \pm 2.08$ & $1.22 \pm 0.69$ \\
\hline
\end{tabular}

*Data represents mean $\pm S D(n=3)$ 
Table 4: Particle size distribution of microcapsules FVI

\begin{tabular}{llll}
\hline Size range $(\boldsymbol{\mu m})$ & Mean size range $(\boldsymbol{\mu m})$ & Number of particles in each range* & \% Frequency $^{*}$ \\
\hline $200-280$ & 240 & $27.00 \pm 1.00$ & $9.00 \pm 0.33$ \\
$281-361$ & 321 & $128.00 \pm 3.61$ & $42.67 \pm 1.20$ \\
$362-442$ & 402 & $68.00 \pm 3.61$ & $22.67 \pm 1.20$ \\
$443-523$ & 483 & $21.67 \pm 0.58$ & $7.22 \pm 0.19$ \\
$524-604$ & 564 & $19.00 \pm 2.00$ & $6.33 \pm 0.67$ \\
$605-685$ & 645 & $10.33 \pm 1.15$ & $3.44 \pm 0.38$ \\
$686-766$ & 726 & $10.67 \pm 3.05$ & $3.56 \pm 1.02$ \\
$767-847$ & 807 & $8.00 \pm 3.00$ & $2.67 \pm 1.00$ \\
$848-928$ & 888 & $4.33 \pm 1.53$ & $1.44 \pm 0.51$ \\
$929-1009$ & 969 & $3.00 \pm 2.00$ & $1.00 \pm 0.67$ \\
\hline
\end{tabular}

*Data represents mean \pm SD $(n=3)$

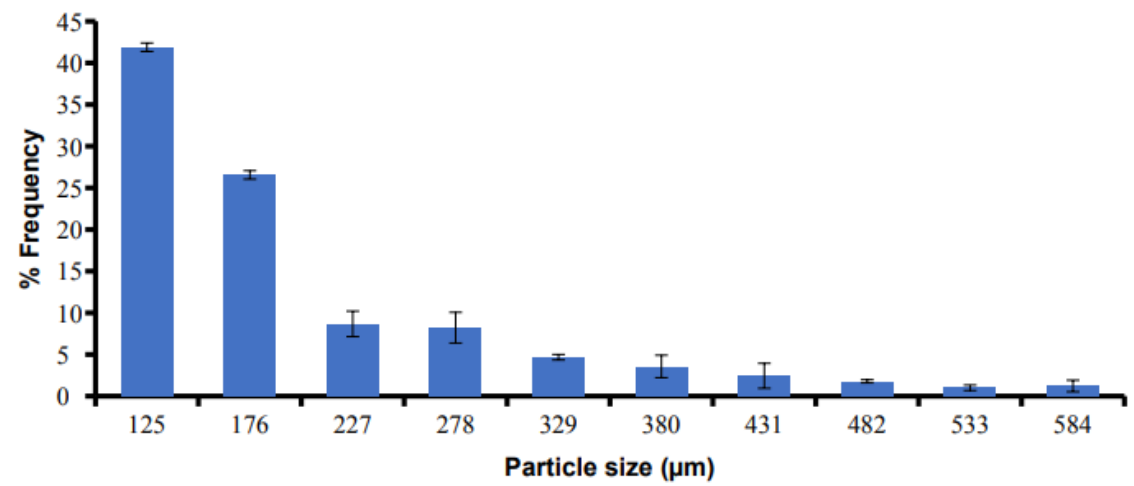

A

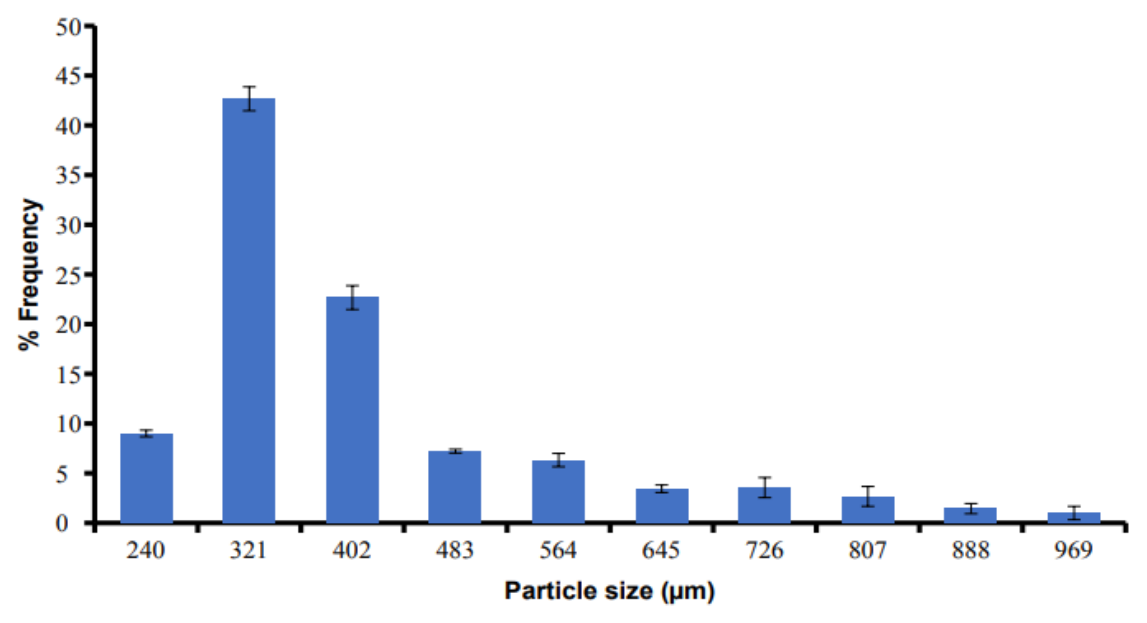

B

Fig. 3: Particle size distribution of microcapsules FIII (A) and FVI (B), ${ }^{*}$ Data represents $m e a n \pm S D(n=3)$

\section{The percentage of curcumin in microcapsules}

The amount of curcumin in the microcapsules was determined by taking $10 \mathrm{mg}$ of the microcapsules. Therefore, the percentage of curcumin in the microcapsules and the entrapment efficiency could be calculated. The result of the curcumin level in microcapsules FIII and FVI were $15.63 \%$ and $5.4 \%(\mathrm{w} / \mathrm{w})$, respectively, and the entrapment efficiency of microcapsules FIII and FVI were $38.46 \%$ and $35.69 \%(\mathrm{w} / \mathrm{w})$, respectively.

\section{Water content}

The water content test aimed to determine the amount of water in the microcapsules. The higher the water content in the preparation, the easier it is for the preparation to be contaminated by microbes. Hence, the water content needs to be controlled. The water content can also affect the stability of microcapsules during storage. The water content of microcapsules FIII and FVI carried out using a Karl Fischer moisture meter were $9.34 \%$ and $8.09 \%(w / w)$, respectively.

\section{Release study of curcumin from microcapsules in vitro}

The release test was conducted within $8 \mathrm{~h}$ to investigate the release mechanism and the duration of curcumin released from the microcapsule matrix system. There was an increase in the percentage of dissolution continuously proportional to time, as shown in fig. 4 , and it can also be seen that the release pattern of curcumin from the microcapsules FVI was a controlled release (table 5) [12]. The percentage of curcumin released from both microcapsules FIII and FVI within $8 \mathrm{~h}$ was higher compared to uncoated curcumin powder. 


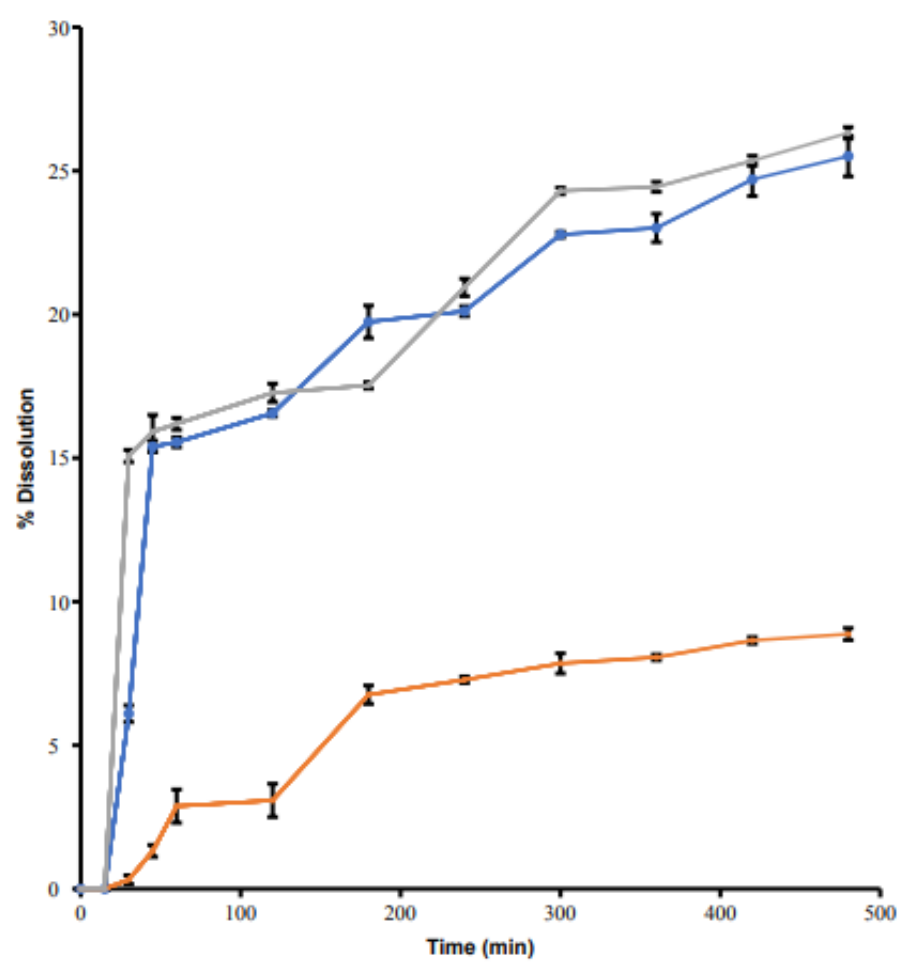

Fig. 4: Release study of uncoated curcumin powder (red)*, microcapsules F1II (blue)*, microcapsules FVI (green)*, 'Data represents mean $\pm \operatorname{SD}(n=3)$

Table 5: Release kinetic model of curcumin from the microcapsules

\begin{tabular}{llll}
\hline Sample & Equation of zero orde r (c vs t) & Equation of first order (log c vs t t) $^{*}$ & ${\text { Higuchi equation (c vs } \sqrt{t})^{*}}^{*}$ \\
\hline Curcumin & $\mathrm{y}=3.9047+0.0030 \mathrm{x}$ & $\mathrm{y}=0.741 \log (\mathrm{x})-10.775$ & $\mathrm{y}=1.6889+1.6753 \mathrm{x}$ \\
& $\mathrm{R}^{2}=0.6142$ & $\mathrm{R}^{2}=0,9614$ & $\mathrm{R}^{2}=0.8114$ \\
Microcapsules FIII & $\mathrm{y}=1.2349 \mathrm{x}+13.537$ & $\mathrm{y}=1,01 \log (\mathrm{x})-2.6922$ & $\mathrm{y}=0.8845 \mathrm{x}+1.8719$ \\
& $\mathrm{R}^{2}=0.8248$ & $\mathrm{R}^{2}=0.9259$ & $\mathrm{R}^{2}=0.9372$ \\
Microcapsules FVI & $\mathrm{y}=0.0266 \mathrm{x}+14,395$ & $\mathrm{y}=0.952 \log (\mathrm{x})-0.5954$ & $\mathrm{y}=1.2349 \mathrm{x}+13.537$ \\
& $\mathrm{R}^{2}=0.9561$ & $\mathrm{R}^{2}=0.8607$ & $\mathrm{R}^{2}=0.8248$ \\
\hline
\end{tabular}

${ }^{*}$ Data represents mean $\pm \mathrm{SD}(\mathrm{n}=3)$

Fig. 4 depicts an increase in the percentage of curcumin dissolution continuously with time. Microcapsules FVI gave rise a controlled release of curcumin (release kinetic model of zero-order, $\mathrm{R}^{2}=$ 0.9561) due to the use of chitosan-ethyl cellulose-GMS [12].
Furthermore, based on Higuchi equation, microcapsules FIII might release curcumin with a mechanism of diffusion $\left(\mathrm{R}^{2}=0.9372\right)$ depending upon its concentration (release kinetic model of the first order, $\mathrm{R}^{2}=0.9259$ ).

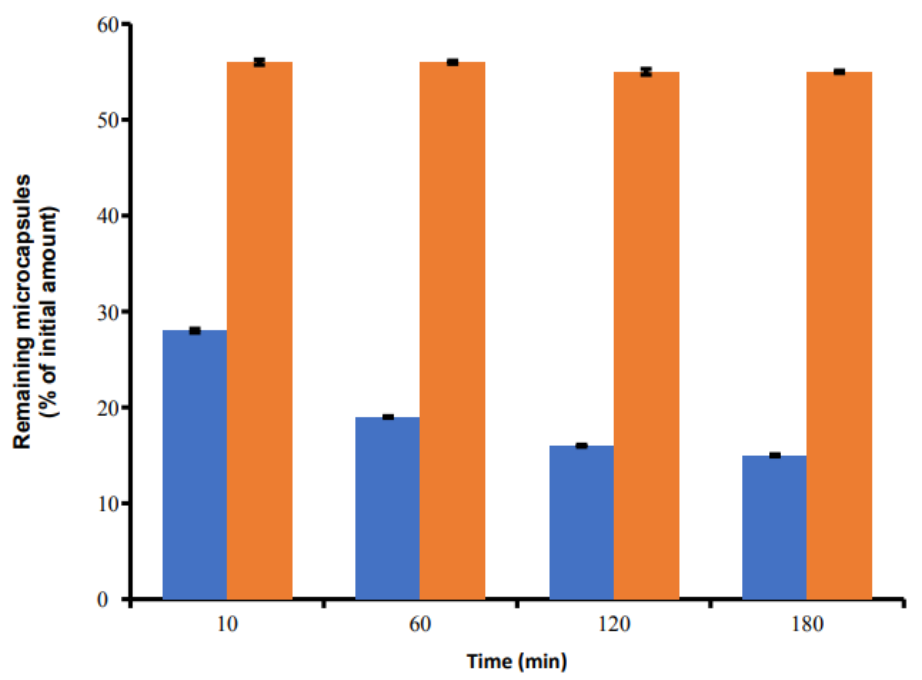

Fig. 5: Mucoadhesive properties of microcapsules FIII (blue)* and FVI (red)*, *Data represents mean \pm SD (n=3) 


\section{Evaluation of mucoadhesive properties}

Mucoadhesive properties were evaluated to determine the amount of the microparticles which was able to adhere on the intestinal mucosa within $3 \mathrm{~h}$. This evaluation was also important for the investigation of the influence of ethylcellulose on the mucoadhesive properties. The amount of uncoated curcumin powder and the microcapsules attached to the intestine decreased with time, as shown in fig. 5. Only a small amount of curcumin remained on the intestinal mucosa. In contrast, the microcapsules devoted a higher percentage of curcumin concentrated on the intestinal mucosa compared to uncoated curcumin powder as chitosan has comparatively good mucoadhesive properties.

\section{DISCUSSION}

In this study, the addition of chitosan, apart from being a polymer matrix, was also used to increase the solubility of curcumin. $1 \%$ $(\mathrm{w} / \mathrm{v})$ ethyl cellulose was added as a polymer matrix to control the release of curcumin. Ethylcellulose is a water-insoluble polymer that has been widely used in the manufacture of sustained release dosage forms of water-soluble drugs. Ethylcellulose can reduce the release of drugs from pharmaceutical preparation. The rate of drug release from the ethylcellulose matrix can be controlled through diffusion and/or an erosion mechanism. Ethylcellulose has been widely used as a coating material for tablets and granules. Moreover, one of the advantages of ethyl cellulose in modified-release preparations is reducing the risk of dose dumping [5-7].

The final mixtures were dried using a spray dryer. The addition of ethyl cellulose and GMS together with chitosan in the formulas can shorten the duration of spray drying as much as $30 \%$ compared to those with chitosan only. The microcapsules were produced by the formation of the solution (FI, FII, FIII) or the suspension (FIV, FV, FVI) with chitosan-ethyl cellulose-GMS as the wall material, followed by spraying in a drying chamber with hot air. All the solvent could evaporate instantly when it came into contact with the hot air, and the wall material was dried to encapsulate curcumin.

Based on the result, the microcapsules FIII displayed spherical shapes without pores which were similar to each other. Thus, the morphology indicated curcumin was homogeneously entrapped in the polymers, namely chitosan and ethylcellulose, as curcumin was soluble in the polymer solution. In addition, the morphology formed can also be affected by the duration of stirring of the final mixture. Since there were no pores on the surface of the microcapsules, the release of curcumin from the microcapsules could demonstrate the diffusion mechanism, which is in agreement with the Higuchi equation based on the release of curcumin from the microcapsules FIII as shown in table 5. While the microcapsules FVI had layers forming the rough surface due to the addition of GMS and a rapid drying process. The presence of GMS has changed the system into a suspension containing curcumin under permanent magnet stirring. Furthermore, GMS could disperse curcumin in the solvent system and curcumin might be evenly entrapped in chitosan used as a hydrophilic polymer, while ethylcellulose is a hydrophobic polymer which can also act as an emulsifying agent. Chitosan added with hydrophobic polymers such as ethylcellulose could stabilize physically and chemically the formed microcapsules. The size of microcapsules could be influenced by the drying technique. The particle size of microcapsules FIII obtained from spray drying was smaller than that of FVI due to the addition of GMS $[5-7,14]$.

The low amount of curcumin entrapped in both microcapsules FIII and FVI might be due to the loss of curcumin during the mixing and the spray drying process. Curcumin could be attached to the dryer chamber and cyclone wall of the spray dryer. Small amounts of curcumin which was soluble in ethanol might have radiated around the dryer chamber and dried on the wall due to ethanol evaporation. Furthermore, the spraying liquid coming out of the nozzle was not able to be converted into the microcapsules felt down on the bottom of the dryer chamber. The spray drying method resulted in microcapsules with lower water content in the presence of GMS. Moreover, the moisture content in the microcapsules can be affected by the inlet and outlet temperatures during the spray drying process [5-7].

The percentages of curcumin released from the microcapsules were still small, thus could keep increasing over time but still higher compared to uncoated curcumin powder. Accordingly, ethylcellulose has an important role in the kinetic release model of the microcapsules. In the case of microcapsules FVI, GMS could preserve the controlled release profile of curcumin $[11,12,15,16,18]$.

Based on the results, chitosan displayed mucoadhesive properties even in the presence of ethyl cellulose. The mucoadhesive properties of the microcapsules could prolong the residence time of curcumin along the gastro intestine tract, thus could render a better therapeutic effect [17-20]. The mucoadhesive properties of the polymer are interfered with the interactions between the mucosa and the polymer and their strength depends upon the structure and charge of polymer mediated by ionic bonds and hydrogen bonds. In addition, physical entanglement also affects the adhesive strength of polymer. Based on fig. 5 , the mucoadhesive properties of the microcapsules FVI was better than those of FIII. GMS in the formulation could protect the binding between the microcapsules and mucus to exert stable mucoadhesive properties during the experiment. Therefore, $55 \%(\mathrm{w} / \mathrm{w})$ microcapsules FVI remained in the mucus after $3 \mathrm{~h}$ of the experiment period [21-24].

\section{CONCLUSION}

Curcumin could be formulated into the microcapsules using a combination of chitosan and ethyl cellulose. In the presence of an ethanolic solution of ethylcellulose, variation in the concentration of chitosan and the use of cosolvent could affect the solubility of curcumin. In this study, curcumin was soluble in $2 \%(\mathrm{w} / \mathrm{v})$ chitosan (FIII and FVI), resulting in spherical microcapsules. It was found that the release of curcumin from the microcapsules could last at least for 8 h. Moreover, the mucoadhesive properties of the microcapsules were better than those of uncoated curcumin powder. GMS has an important role in the preservation of both mucoadhesive properties and the controlled release profile of curcumin from the microcapsules that could lead to a better therapeutic effect of curcumin.

\section{ACKNOWLEDGEMENT}

The authors gratefully acknowledge financial support from Ristek DIKTI Indonesia (World Class Research).

\section{FUNDING}

World-Class Research DIKTI Indonesia.

\section{AUTHORS CONTRIBUTIONS}

All the authors contributed equally.

\section{CONFLICT OF INTERESTS}

Declared none

\section{REFERENCES}

1. Heger M, van Golen RF, Broekgaarden M, Michel MC. The molecular basis for the pharmacokinetics and pharmacodynamics of curcumin and its metabolites in relation to cancer. Pharmacol Rev. 2014;66(1):222-307. doi: 10.1124/pr.110.004044. PMID 24368738.

2. Harit J, Barapatre A, Prajapati M, Aadil KR, Senapati S. Antimicrobial activity of rhizome of selected curcuma variety. Int J Life Sci BT Pharm Res. 2013;2:183-9.

3. Desobry SA, Netto FM, Labuza TP. Comparison of spray-drying, drum-drying and freeze-drying for $\beta$-carotene encapsulation and preservation. J Food Sci. 1997;62(6):1158-62. doi: 10.1111/j.1365-2621.1997.tb12235.x.

4. Baranauskiene R, Bylaite E, Zukauskaite J, Venskutonis RP. Flavor retention of peppermint (Mentha piperita L.) essential oil spray-dried in modified starches during encapsulation and storage. J Agric Food Chem. 2007;55(8):3027-36. doi: 10.1021/jf062508c, PMID 17381102.

5. Sosnik A, Seremeta KP. Advantages and challenges of the spraydrying technology for the production of pure drug particles and drug-loaded polymeric carriers. Adv Colloid Interface Sci. 2015;223:40-54. doi: 10.1016/j.cis.2015.05.003, PMID 26043877.

6. Annamalai J, Kothari DC, Gudipati V. Microencapsulation of fish oil-milk based emulsion by spray drying: impact on oxidative stability. Fish Technol. 2014;51:31-7. 
7. Bortnowska G. Multilayer oil-in-water emulsions: formation, characteristics and application as the carriers for lipophilic bioactive food components- a review. Pol J Food Nutr Sci. 2015;65(3):157-66. doi: 10.2478/v10222-012-0094-0.

8. Rahmat D, Kumala S, Farida Y, Chandra B. Antibacterial activity of ethanolic extract of Javanese turmeric rhizome entrappted in nanoparticles: a novel rule of chitosan. Int J App Pharm. 2018;10(6):298-302. doi: 10.22159/ijap.2018v10i6.28521.

9. Rahmat D, Farida Y, Brylianto AT, Sumarny R, Kumala S. Antidiabetic activity of nanoparticles containing Javanese turmeric rhizome extract: the strategy to change particle size. Int J App Pharm. 2020;12:90-3. doi: 10.22159/ jap.2020v12i4.36249.

10. Martin A, Swarbrick J, Cammarata A. Physical pharmacy: physical chemical principles in the pharmaceutical sciences. 3rd ed. Philadelphia: Lea and Febiger; 1983.

11. Murtaza G, Ahamd M, Akhtar N, Rasool F. A comparative study of various microencapsulation techniques: effect of polymer viscosity on microcapsule characteristics. Pak J Pharm Sci. 2009;22(3):291-300. PMID 19553177.

12. Song L, He S, Ping Q. Development of a sustained-release microcapsule for delivery of metoprolol succinate. Exp Ther Med. 2017;13(5):2435-41. doi: 10.3892/etm.2017.4247, PMID 28565860.

13. Ijaz M, Matuszczak B, Rahmat D, Mahmood A, Bonengel S, Hussain S, Huck CW, Bernkop-Schnürch A. Synthesis and characterization of thiolated $\beta$-cyclodextrin as a novel mucoadhesive excipient for intra-oral drug delivery. Carbohydr Polym. 2015;132:187-95. doi: 10.1016/j.carbpol.2015.06.073, PMID 26256340.

14. Kandansamy K, Somasundaram PD. Microencapsulation of colors by spray drying- a review. Int J Food Eng. 2012;8(2):115. doi: 10.1515/1556-3758.2647.

15. Mohammed NK, Tan CP, Manap YA, Muhialdin BJ, Hussin ASM. Spray drying for the encapsulation of oils-a review. Molecules.
2020;25(17):1-16. doi: 10.3390/molecules25173873, PMID 32858785 .

16. Azadi S, Ashrafi H, Azadi A. Mathematical modeling of drug release from swellable polymeric nanoparticles. J Appl Pharm Sci. 2017;7:125-33.

17. Jain P, Bhatt DC, Jindal DK. Recent advances in mucoadhesive microsphere-based novel drug delivery systems. Int J Biopharm. 2019;10:9-16.

18. Ravi Kumar MNR. Nano and microparticles as controlled drug delivery devices. J Pharm Pharm Sci. 2000;3(2):234-58. PMID 10994037.

19. Kumar RS, Radha GV, Yagnesh TNS. Mucoadhesive microencapsulation: a new tool in drug delivery systems. World J Pharm Pharm Sci. 2016;12:1410-70.

20. Komati S, Swain S, Rao MEB, Jena BR, Dasi V. Mucoadhesive multiparticulate drug delivery systems: an extensive review of patents. Adv Pharm Bull. 2019;9(4):521-38. doi: 10.15171/apb.2019.062, PMID 31857957.

21. Wasilewska K, Winnicka K. Ethylcellulose-a pharmaceutical excipient with multidirectional application in drug dosage forms development. Materials (Basel). 2019;12(20):1-21. doi: 10.3390/ma12203386, PMID 31627271.

22. Prasad SN, Patel HK, Gothoskar AV. Qbd-based development and evaluation of enteric coated mucoadhesive microcapsules of amoxicillin trihydrate as a novel chronotherapeutic approach for treatment of bacterial infections. Int J Pharm Pharm Sci. 2018;10(8):90-100. doi: 10.22159/ijpps.2018v10i8.27699.

23. Saritha T, Anna B, Jaswanth A. Design and evaluation of forskolin buccal mucoadhesive microspheres. Int J Curr Pharm Res. 2015;7:17-21.

24. Samran S, Dalimunthe D, Dalimunthe D, Dalimunthe D. The formulation of dry curcuma (Curcuma xanthorrhiza Roxb.) extract microcapsules by spray wet microencapsulation techniques. Asian J Pharm Clin Res. 2018;11(3):226-9. doi: 10.22159/ajpcr.2018.v11i3.22608. 